\title{
QUATRO PERGUNTAS PARA AS CIÊNCIAS SOCIAIS NA PANDEMIA ${ }^{1}$
}

Four questions for the Social Sciences in the Pandemic ${ }^{2}$

PLEYERS, Geoffrey ${ }^{3}$

Resumo: Cientistas sociais mostraram que a pandemia COVID-19 não é apenas uma crise sanitária. É também uma crise social e política, e deve ser tratada como um momento de ruptura que trará grandes mudanças em nossas vidas, nossas sociedades e nosso mundo. Embora muitas vezes deixadas de lado pelos formuladores de políticas, as contribuições das ciências sociais para lidar com a pandemia do coronavírus têm sido tão importantes e, de muitas maneiras, complementares às ciências exatas. A pandemia gerou um ciclo de desglobalização. Os estados fecharam suas fronteiras, as viagens e a mobilidade ao redor do mundo diminuíram drasticamente. Grandes eventos internacionais foram cancelados ou adiados. As famílias se isolaram em suas casas e a prioridade dos governos nacionais é garantir o acesso a equipamentos de saúde para proteção contra o vírus e suprimentos básicos para "seu próprio povo". No entanto, isso está acontecendo globalmente. É necessária uma sociologia mais global para melhor compreender e enfrentar os desafios que enfrentamos, para reunir boas práxis e exemplos de sucesso, para alertar sobre as ameaças e para pensar sobre o mundo que sairá desta crise global. Tal perspectiva global não deve ceder ao "globalismo metodológico" e se limitar a macroanálises. Cientistas sociais sublinharam o fato de que a crise também pode ser uma oportunidade para reconstruir o mundo de uma maneira diferente. Muitos enfatizam a necessidade de um mundo mais sensível e atento aos direitos humanos, aos cuidados e às desigualdades sociais, e com sistemas públicos de saúde mais fortes. Também nas ciências sociais, precisamos aprender com a experiência da pandemia de outros países e outras regiões do mundo.

Palavras-chave: COVID-19. Ciências Sociais. Pandemia.

Abstract: Social scientists have shown that the COVID-19 pandemic is not only a sanitary crisis. It is also a social and political crisis, and should be treated as a moment of rupture that will bring major changes into our lives, our societies and our world. While often sidelined by policy makers, social sciences' contributions in dealing with the coronavirus pandemic have been as important as, and in many ways complementary to, hard sciences. The pandemic has

\footnotetext{
${ }^{1}$ Recebido em: 1ํ Mai. 2020 | Aceito: 25 Ago. 2020.

2 Traduzido por Professor André Magnelli (prof.andremagnelli@gmail.com).

3 Pesquisador do FNRS (Belgian Fund for National Research) do CriDIS (Centre for interdisciplinary research: democracy, institutions, subjectivity) e professor da Université Catholique de Louvain. Vice-President of the International Sociological Association. https://uclouvain.academia.edu/GeoffreyPleyers
}

REALIS, v.10, n. 01, Jan-Jun. 2020 - ISSN 2179-7501 
generated a cycle of de-globalization. States have closed their borders, travelling and mobility around the world have sharply reduced. Major international events have been canceled or postponed. Families have isolated themselves at their homes and national governments' priority is to secure access to healthcare equipment to protect against the virus and basic supplies to "their own people". This is however happening globally. A more global sociology is required to better understand and tackle the challenges we face, to gather good praxis and successful examples, to warn about threats and to think about the world that will emerge out of this global crisis. Such a global perspective should not yield to "methodological globalism" and be limited to macro-analyses. Social scientists have underlined the fact that the crisis may also be an opportunity to rebuild the world in a different way. Many stress the need for a world more sensitive and attentive to human rights, care and social inequalities, and with stronger public healthcare systems. In social sciences also, we need to learn from other countries and other world regions' experience of the pandemic.

Keywords: COVID-19. Social Sciences. Pandemic.

O coronavírus trouxe a ciência de volta ao centro do espaço público, mesmo em países onde os líderes populistas costumavam deslegitimá-la. Epidemiologistas, médicos e biólogos nos trazem fatos difíceis: a pandemia progride a cada dia; é muito pior do que uma "gripe forte"; e ceifa milhares de vidas em todos os continentes. Os cientistas sociais apresentaram fatos que são tão duros quanto inquestionáveis: embora o vírus em si seja um agente biológico que pode infectar qualquer um de nós, somos profundamente desiguais quando confrontados com ele. As políticas de saúde pública e as desigualdades sociais importam pelo menos tanto quanto a forma como nossos corpos reagem a ele quando se trata das consequências mortais do vírus. Os cientistas sociais demonstraram que a pandemia da COVID-19 não é apenas uma crise sanitária. É também uma crise social e política, e deve ser tratada como um momento de ruptura que trará grandes mudanças em nossas vidas, nossas sociedades e nosso mundo. Embora frequentemente marginalizadas pelos formuladores de políticas, as contribuições das ciências sociais para lidar com a pandemia do coronavírus têm sido tão importantes quanto as das ciências duras, sendo-lhes de muitas maneiras complementares.

REALIS, v.10, n. 01, Jan-Jun. 2020 - ISSN 2179-7501 
Fazendo eco do forte retorno dos Estados-Nação que se apresentaram como os únicos atores-chave para decidir e controlar a resposta à eclosão do vírus, muitas contribuições das ciências sociais tem se concentrado na escala nacional e se dirigido aos concidadãos e formuladores de políticas de seus países. Especialistas realizaram estudos estatísticos nacionais, analisaram o impacto diferenciado do vírus entre classes e raças em seu país, região ou cidade, examinaram as políticas de seus governos nacionais para lidar com a crise e contribuíram para o debate público nacional.

Esta ascensão do nacionalismo metodológico é um paradoxo, pois a pandemia de COVID-19 é um fenômeno profundamente global e um resultado intrínseco de nossa Era Global (Albrow, 1996). A pandemia gerou um ciclo de desglobalização. Os Estados fecharam suas fronteiras, as viagens e a mobilidade ao redor do mundo reduziram drasticamente. Os principais eventos internacionais foram cancelados ou adiados. As famílias se isolaram em suas casas e a prioridade dos governos nacionais é garantir o acesso a equipamentos de saúde para proteção contra o vírus e suprimentos básicos para "seu próprio povo". No entanto, isto está acontecendo globalmente. 0 vírus não se detém nas fronteiras fechadas e revela o quão profundamente conectados e interdependentes nos tornamos. Ele se espalhou mais rápido e mais amplamente do que qualquer pandemia anterior, graças à circulação sem precedentes de seres humanos pelo mundo. 0 confinamento e a ameaça do vírus abalaram profundamente as sociedades e as vidas em todo o mundo. É um evento global que se cruza com a vida cotidiana de cada ser humano no planeta.

A colaboração internacional em escala global é crucial para lidar com a pandemia. É certamente verdade nos campos da medicina e das ciências naturais para se chegar a uma melhor compreensão do vírus em si. Os pesquisadores chineses isolaram e sequenciaram o genoma do vírus em janeiro e comunicaram os resultados de dezenas de estudos científicos, abrindo o caminho para a publicação de milhares de artigos de periódicos dedicados à COVID-19 por médicos, virologistas e epidemiologistas de todo o mundo. Aprender com a experiência, o fracasso e as boas práticas é fundamental para alcançar uma melhor 
compreensão do novo vírus, para estabelecer melhores tratamentos que podem salvar milhares de vidas e para mitigar a propagação da pandemia.

Também nas ciências sociais, precisamos aprender com a experiência de outros países e de outras regiões do mundo sobre a pandemia. Uma sociologia mais global é necessária para melhor compreender e enfrentar os desafios que se apresentam diante da pandemia, para reunir boas práticas e exemplos de sucesso, para alertar sobre as ameaças e para pensar no mundo que emergirá desta crise global.

Tal perspectiva global não deve ceder ao "globalismo metodológico" e ser limitada a macroanálises. Fomentar uma perspectiva global não significa descartar a escala nacional. Pelo contrário, precisamos combinar e articular escalas de ação e níveis de análise, do local ao global, e da subjetividade pessoal à globalização. Uma perspectiva global adequada exige insights empíricos, epistêmicos e analíticos de diferentes regiões do mundo, totalmente incrustados em uma realidade que é ao mesmo tempo local, nacional, regional e global. Portanto, urge fomentar o diálogo entre cientistas sociais de todos os continentes e combinar análises nas escalas local, nacional, regional e global e da subjetividad pessoal à globalização.

No mundo das redes sociais digitais, dos líderes populistas e do crescimento das teorias da conspiração, a pandemia foi rapidamente acompanhada por uma "infodemia" com uma rápida e intensa circulação de falsas notícias e teorias de interpretação da crise por atores de extrema direita. Por outro lado, assistimos a um crescente controle da informação em países autoritários e semi-autoritários; a uma restrição da liberdade de pensar e pesquisar em países com líderes populistas e autoritários; e tentativas de intimidação de jornalistas e pesquisadores em países democráticos. Frente a essa "infodemia" e da vontade dos atores políticos de influir sobre a informação que trata da pandemia, as Ciências Sociais têm uma missão histórica: entender melhor a crise multidimensional, suas possíveis consequências e os desafios globais que ela revela e amplifica.

Nesta época histórica, as ciências sociais têm muito que contribuir com análises rigorosas, perspectivas críticas e propostas para um mundo mais justo. Essas contribuições se concentram em quatro conjuntos de desafios e debates: 
(1) revelar e analisar as dimensões sociais da pandemia;

(2) monitorar e analisar as formas como os regimes políticos e os governos nacionais enfrentaram a crise e como estes revelam suas fraquezas;

(3) analisar a forma como a pandemia e o confinamento afetaram profundamente os indivíduos e as sociedades, reconfigurando as relações sociais, e como os atores sociais implementam novas formas de solidariedade e modos de viver neste contexto tão peculiar;

(4) e como a crise e a forma como os atores sociais lidam com ela podem ter consequências a longo prazo, pavimentando o caminho para futuros alternativos que possam sair dela.

\section{As dimensões sociais da pandemia}

A primeira missão das ciências sociais é avaliar o contexto atual e a forma como o vírus afeta nossa sociedade, com rigor e em uma perspectiva crítica. Os cientistas sociais têm contribuído para fornecer e discutir indicadores que permitem monitorar a pandemia. Eles revelaram que, embora o vírus possa infectar cada ser humano, a pandemia nos afeta de maneira diferente e a maneira como o vírus é tratado está intimamente ligada a fatores sociais. A pandemia de COVID-19 exacerba as desigualdades sociais e revela as estruturas sociais, notadamente em termos de classe, raça e gênero. Calcula-se que nos Estados Unidos, os latinos e asiáticos têm 1,5 vezes mais possibilidade de serem afetados e morrer por conta do vírus do que os brancos; os negros, 2 vezes mais (Rubin-Miller, Alban, Artiga \& Sullivan, 2020). Na França, nos subúrbios populares de Paris, houve um aumento de $72 \%$ da mortalidade durante o primeiro mês de internação. Uma abordagem interseccional (Hill Collins \& Bilge, 2016) é, portanto, crucial para entender como a crise é vivida (u sobrevivida) e porque a maneira como a enfrentamos é profundamente desigual e injusta. Não podemos 
entender o impacto da pandemia nas nossas sociedades sem dedicar uma atenção particular às opressões que sofrem as mulheres não brancas e à forma desproporcional como compõem a primeira linha dos atores que cuidam dos doentes e que permite que nossas sociedades sigam adiante em seus setores indispensáveis.

A desigualdade econômica está agregada às desigualdades urbanas. Em todas as regiões do mundo, o vírus tem um impacto devastador nas comunidades mais vulneráveis: desde as favelas do Rio de Janeiro até os imensos "slums" de Mumbai, passando pelos campos de refugiados na Europa e os "bidonvilles" que voltaram a aparecer nas cidades do norte. Os habitantes das favelas não podem deixar de trabalhar durante a semana e nem estocar alimentos, o que aumenta a exposição ao vírus fora da sua comunidade. 0 confinamento deixa os trabalhadores do setor informal sem renda enquanto o vírus se propaga rapidamente nas casas e ruas muito densas das favelas.

A pandemia provoca não apenas uma crise sanitária. Revela e intensifica crises existentes, sejam elas econômicas, sociais, políticas ou ecológicas. Em todos os campos da sociologia, desde a educação até o trabalho, a pandemia atua como um espelho através do qual podemos ver e analisar os problemas das nossas sociedades e as mudanças que estavam em marcha e se fortaleceram com o confinamento, como a digitalização ou aprofundamento das desigualdades. As consequências trágicas da pandemia nos bairros mais pobres e setores populares "é um alerta do mundo pouco humanos que vivemos" (Ramírez, 2020).

\section{A governança da COVID-19}

Um segundo conjunto de contribuições das ciências sociais analisa a forma como os governos, formuladores de políticas e regimes políticos lidam com a propagação do vírus.

Os Estados-nação se apresentaram como os principais atores encarregados de lidar com a pandemia. Esta força renovada dos Estados Nação e das comunidades nacionais não é um fenômeno novo. Está no centro da emergência da China como potência global há décadas 
e tornou-se o centro da política nacional e internacional dos Estados Unidos com Donald Trump. Durante a última década, testemunhamos a ascensão de líderes populistas e/ou autoritários do Estado que colocaram o nacionalismo e o autoritarismo de volta como uma característica importante de nosso tempo. Este retorno do nacionalismo e dos Estados atingiu um nível ainda maior com o surto da COVID-19. Os Estados fecharam suas fronteiras e os cidadãos se voltaram para seus governos nacionais para proteção, cuidado e diretrizes. As instituições internacionais desapareceram na crise global, iniciando pela ONU. A solidariedade internacional sofreu um de seus declínios mais fortes na história recente e a busca por uma vacina parece mais uma corrida global entre corporações transnacionais do que um desafio científico comum.

A pandemia revelou as forças e as limitações dos sistemas políticos nacionais. A falta de eficiência de um governo nacional ou discursos reiterados de um líder estatal zombando da pandemia e atrasando as medidas de confinamento pode resultar em milhares de mortes adicionais. A maioria dos governos não avaliou a importância da pandemia a tempo e falhou em fornecer proteções básicas contra a propagação do vírus para seus trabalhadores da saúde, sem mencionar toda a população. Confrontados com esta inesperada crise sanitária, cada governo estabeleceu sua necropolítica. Através de suas políticas, os governos dão menos oportunidades para que algumas pessoas lidem com o vírus do que para outras, enquanto as pessoas que morrem em casa ou em lares de idosos não aparecem nas estatísticas públicas da maioria dos países. A pandemia e o bloqueio também transformaram a relação entre os cidadãos e o governo. Os cidadãos recorrem aos governos nacionais para oferecer proteção, cuidados e as diretrizes para sair da pandemia. Muitos deles aceitam um controle social mais forte pelo Estado e novas tecnologias de vigilância e reconhecimento facial como um preço a pagar para limitar a pandemia e sair do confinamento. Em todo o mundo, governos autoritários, populistas e liberais tendem a esconder suas próprias falhas e limitações ao lidar cedo com a crise, colocando a culpa da crise em cidadãos individuais que não cumprem as ordens de confinamento. 
Os cientistas sociais analisaram como os regimes políticos respondem à pandemia e aos desafios que ela representa para cada um deles. Os primeiros fracassos do partido comunista chinês em lidar com a nova doença apontaram para as limitações dos regimes autoritários, mas o governo chinês lidou com a epidemia e agora usa sua experiência e a ajuda que presta a outros países para fortalecer sua diplomacia. Por outro lado os líderes populistas foram desafiados, pois o vírus não pode ser reduzido a uma gripe ou encapsulado em notícias falsas. A negação da ciência por líderes populistas levou-os a postergar ou até mesmo se opor às medidas de confinamento, o que facilitou a rápida difusão do vírus em seus países e gerou um grande número de vítimas.

A pandemia também levanta desafios para a democracia, pois enfatiza as desigualdades e, como alguns defendem, o aumento do controle social como uma necessidade. A situação de emergência revelou o impacto de anos de cortes de verbas públicas, desmantelamento do Estado e privatização das instituições públicas de saúde e seguridade social. Nos países que carecem de um sistema de assistência social consolidado, a crise sanitária rapidamente se transformou em uma crise humanitária. Frente a pandemia é necessária a reafirmação dos valores fundamentais do sistema democrático, pelo qual as decisões são baseadas no conhecimento científico e no monitoramento e participação dos cidadãos, com um Estado capaz de garantir o acesso de todos à saúde pública. Em um discurso histórico, no dia 18 de março, Angela Merkel resumiu o desafio em três frases: "Somos uma democracia. Não vivemos de imposições, mas sim de conhecimento compartilhado $e$ participação. Essa é uma tarefa histórica e só poderemos superá-la unidos ${ }^{4 \prime}$.

\section{A experiência da pandemia}

Sendo a pandemia um fenômeno global, é grande a tentação para os cientistas sociais de limitarem-se a análises "macro", copilando estatísticas, analisando políticas nacionais ou

\footnotetext{
${ }^{4}$ https://www.bundesregierung.de/breg-de/themen/coronavirus/ansprache-der-kanzlerin-1732108
}

REALIS, v.10, n. 01, Jan-Jun. 2020 - ISSN 2179-7501 
os impactos econômicos. São as partes mais visíveis da pandemia. Para entendê-la, no entanto, é indispensável olhar para a experiência da pandemia tal como vivida no cotidiano.

As medidas de distanciamento social colocaram em risco a solidariedade, desafiaram seu significado e muitas vezes encolheram os limites da comunidade dentro da qual ela ocorre. Os coletivos que receberam pouca consideração provaram ser cruciais para manter a sociedade a funcionar. Enfermeiros e prestadores de cuidados arriscam suas vidas para cuidar de pacientes e pessoas idosas. Os caixas dos supermercados tornaram-se visíveis como pessoas que desempenham um papel importante na vida diária dos cidadãos. Novas redes de solidariedade surgiram em bairros e cidades. A economia social e solidária está fornecendo caminhos para uma economia mais re-localizada. Por outro lado, também testemunhamos a limitação da solidariedade às comunidades nacionais fechadas ou às famílias.

Este conjunto de análises também explora os profundos impactos do fechamento na vida das pessoas, na subjetividade e nas relações sociais. As relações intergeracionais tomaram novas formas e significados. As tecnologias digitais assumiram um papel importante na manutenção das relações sociais, desde as amizades até a redefinição das relações amorosas sob condições de confinamento.

A sociologia assenta sua análise sobre a experiência que constitui o confinamento e a pandemia para cada um. É uma situação que se vive de maneira distinta segundo as condições materiais e sociais de cada um, de cada país, de cada lugar. Para muitos, se tornou uma experiência que se vive no espaço físico e no mundo da internet, inundada por um desfile permanente de informações globais e conectado a redes familiares, de amizade e profissionais através das redes sociais.

A pandemia nos questiona no mais profundo do nosso ser. Ela mostrou a nossa vulnerabilidade como seres biológicos, humanos, sociais e espirituais. Junto com o confinamento e o medo do contágio, teve um impacto profundo na subjetividade dos indivíduos, em sua concepção de si mesmo e em sua projeção como atores de sua própria vida (a subjetivação), em sua relação com os demais e com a sociedade. As vias para enfrentar 
essa crise, formuladas por ativistas e intelectuais feministas, revela uma base fundamental para repensar a vida e o mundo a partir do cotidiano.

Pelo confinamento, o necessário distanciamento social e o medo do contágio, a pandemia sacudiu também nossas relações com os demais. Desde o jardim de infância e creches e também no seio familiar, nossas crianças aprendem a evitar o contato físico, que o espaço público é um espaço de riscos para a saúde e que cantar pode ser perigoso. Quais consequências terão em sua maneira de ser, sua subjetividade, sua sociabilidade e sua maneira de fazer parte da sociedade? Reestabelecer as solidariedades e as relações interpessoais na qual o cuidado, a convivência e a atenção ao outro (Martins, 2020) são maneiras de reconstruir a esperança em espaços de solidariedade e de emancipação, de nos opormos a um modelo de sociedade centrado no egoísmo ou no hiper-utilitarismo, e iniciar outro mundo em meio a essa crise.

No auge da pandemia e do confinamento, se multiplicaram, em todas as regiões do mundo, redes de solidariedade e ajuda mútua nos bairros e cidades (Pleyers, 2020b). No entanto, temos também que analisar como levou muitos indivíduos a se fecharem a outros, enfocados na proteção de sua família, assim como o aumento do racismo étnico e de um racismo "anti-pobres" em várias partes. A pandemia gerou um crescimento do racismo em todas as regiões do mundo: contra os trabalhadores migrantes na Índia ou na China, contra os asiático-americanos nos Estados Unidos, contra as minorias e os pobres acusados de propagar a doença. E, em todo o mundo, contra os refugiados. O Secretário Geral das Nações Unidas alertou para um "tsunami de ódio e xenofobia, bodes expiatórios e alarmismo" desencadeado pela pandemia. “À medida que as especulações giravam em torno do lugar de origem do vírus, os migrantes e refugiados foram vilipendiados como fonte do vírus e tiveram negado acesso a tratamento médico. Enquanto isso, jornalistas que denunciavam as irregularidades, os profissionais de saúde, os trabalhadores humanitários e os defensores de direitos humanos estão sendo atacados simplesmente por fazer seu trabalho5".

5 UN Secretary-General Denounces 'Tsunami' of Xenophobia Unleashed amid COVID-19, NYC: UN. https://www.un.org/press/en/2020/sgsm20076.doc.htm 


\section{Será que um novo mundo sairá da crise?}

O quarto conjunto de análises trata do impacto a longo prazo da pandemia e da forma como a sociedade lida com ela. Como uma crise global de tamanho e consequências inesperadas, a COVID-19 abriu novos horizontes de possibilidades e pode ser aproveitada como uma oportunidade para remodelar o mundo de uma maneira diferente. A crise abalou o dogma econômico que tem governado o mundo por décadas. 0 déficit orçamentário do Estado e até mesmo o dogma do crescimento econômico foi (temporariamente) colocado em espera, já que os governos se concentram em mitigar a pandemia.

Os cientistas sociais têm sublinhado o fato de que a crise também pode ser uma oportunidade para reconstruir o mundo de uma maneira diferente. Muitos enfatizam a necessidade de um mundo mais sensível e atento aos direitos humanos, aos cuidados e às desigualdades sociais, e com sistemas públicos de saúde mais fortes. Novas teorias críticas e sobretudo teorias críticas que encontram nova ressonância nessa crise, como a perspectiva do cuidado e da vulnerabilidade.

Entretanto, crises anteriores mostraram que estas esperanças de um mundo mais justo são apenas um dos vários futuros alternativos que a crise pode abrir. A forma como a pandemia tem sido gerenciada até agora tem escolhido a competição em vez da solidariedade, tanto na sociedade como entre as nações. Os mais ricos sairão da crise muito mais fortes. Ao invés de aumentar a solidariedade em nível nacional e internacional, a pandemia pode levar indivíduos e Estados a priorizar a proteção de sua própria comunidade em detrimento de interesses globais compartilhados. Os atores mais capazes de agarrar as oportunidades após a ruptura do dogma econômico podem não ser aqueles a favor de melhores serviços públicos e de saúde para todos. Nos Estados Unidos, como na maioria dos países, pacotes de ajuda econômica maciça canalizaram enormes quantidades de dinheiro público para resgatar as corporações nacionais da crise. Tanto para as empresas como para 
os países, aqueles que sairão mais rapidamente da crise terão uma vantagem significativa na competição global, como a China parece demonstrar.

A pandemia também pode pavimentar o caminho para uma nova era autoritária, com a biopolítica alicerçada em novas tecnologias e inteligência artificial. Parte da população aceita o aumento da vigilância e do monitoramento estatal para limitar a propagação do vírus. Os regimes autoritários ou líderes são considerados como fornecedores eficientes de soluções e proteção, e a China está se baseando em seu pronto gerenciamento da epidemia para conquistar novos mercados e divulgar seu modelo de governança. Em termos de biopolítica e controle social, a fronteira entre a democracia e os regimes autoritários tem sido difusa, pois o bloqueio limitou os protestos sociais em alguns países e se mostrou útil para confinar e controlar a população dos subúrbios mais pobres.

A maneira como a humanidade sairá da pandemia de COVID-19 dependerá das ciências e pesquisas para descobrir uma vacina, mas também dos resultados de uma luta contínua sobre o significado social, político e geopolítico da pandemia e do mundo que dela sairá. É preciso analisar em profundidade a batalha que travam diversos atores sociais para impor um significado à crise e a partir disso contribuir para forjar o mundo que emergirá dela (Pleyers, 2020a). Essa batalha não termina com o pico da pandemia ou com o confinamento social. Esta é apenas uma das muitas etapas de uma longa luta para redefinir não apenas os modelos sociais, mas também a economia mundial e os regimes políticos do século XXI.

Para cumprir com esta missão, os pesquisadores têm que combinar a capacidade de levar em conta os acontecimentos recentes e em curso, sem limitar a análise à urgência e a perspectivas de curto prazo. 0 desafio é metodológico, empírico, analítico e também teórico. Neste sentido, o fortalecimento de novas perspectivas teóricas críticas, e em particular as que surgiram dos movimentos sociais das últimas décadas, como as perspectivas feministas, decoloniais e ecologistas, são contribuições fundamentais.

Para além de uma crise sanitária como grandes consequências econômicas e sociais, a pandemia da COVID-19 revelou o tamanho da crise multidimensional que afeta nossas 
sociedades em nível nacional e global, e que encontrou sua denominação mais evidente nos movimentos sociais e intelectuais latino-americanos: uma crise de civilização. Vivemos uma época na qual é crucial combinar análise da situação e alternativas práticas imediatas para limitar o impacto devastador da pandemia com a capacidade de identificar os desafios mais profundos do que nos coloca esta crise histórica. 0 que está em jogo nada mais é do que a nossa capacidade de redefinir o que é ser humano e de viver juntos em um planeta limitado que é nosso lugar comum.

\section{Referências}

ALBROW M. (1996) The Global Age, Cambridge: Polity.

HILL COLLINS P., BILGE S. (2016). Intersectionality, London: Polity Press.

MARTINS P.H. (2020) El coronavirus, el don y los escenarios posneoliberales, In: B. Bringel \& G. Pleyers coord. Alerta global. Políticas y movimientos en tiempos de pandemia, Buenos Aires: CLACSO, p. 367-375.

PLEYERS G. (2020) L'entraide et la solidarité comme réponses des mouvements sociaux à la pandémie, Revue du MAUSS, vol.56.

PLEYERS G. (2020) The Pandemic is a battlefield. Social movements in the COVID-19 lockdown, Journal of Civil Society, www.tandfonline.com/doi/full/10.1080/17448689.2020.1794398

RAMÍREZ R. (2020) Dictaduras democráticas, autoritarismo neoliberal y revueltas populares en tiempos de COVID-19, Ciudad de México: CELAG. https://www.celag.org/wpcontent/uploads/2020/06/covid-dictaduras-democraticas-web.pdf

RUBIN-MILLER L., ALBAN C., ARTIGA S., SULLIVAN S. (2020) “COVID-19 Racial Disparities in Testing, Infection, Hospitalization, and Death: Analysis of Epic Patient Data", New York: KFF report. https://www.kff.org/coronavirus-COVID-19/issue-brief/COVID-19-racialdisparities-testing-infection-hospitalization-death-analysis-epic-patient-data 